\title{
FAKTOR-FAKTOR YANG BERHUBUNGAN DENGAN PRODUKTIVITAS DAN KONTRIBUSI PENGHASILAN TENAGA KERJA WANITA PEMETIK TEH DI PTP. NUSANTARA VI KAYU ARO KABUPATEN KERINCI PROPINSI JAMBI
}

\author{
Basuki Sigit priyono ${ }^{1}$ \\ Indra Cahyadinata ${ }^{1}$ \\ Setiowati ${ }^{2}$ \\ 1 Staff Pengajar Jurusan Sosial Ekonomi Pertanian Fak. Pertanian UNIB \\ ${ }^{2}$ Alumni Jurusan Sosial Ekonomi Pertanian Fak. Pertanian UNIB
}

\begin{abstract}
The research was conducted in PTP Nusantara VI Kayu Aro, Regency of Kerinci, Jambi Province on July to August 2006. The respondents were daily fix employees (DFE) of female tea picker, research location was chosen purposively. Aims of the research are: to estimate the productivity level, income level and contribution level to the family income of tea picker female worker in PTP Nusantara VI Kayu Aro Regenci of Kerinci, Jambi Province. Sampling conducted by Simple Random Sampling, total samples are 102 respondents of 1,011 people population. Statistic analysis used in the research is Rank Spearman (rs) correlation test by reliability level $95 \%(\alpha / 2=$ 0.025) and to examine the significance level used two tailed t-test. In order to describe the characteristic and income level were used central measurement or score average of whole respondents as categorizing used value rank (interval). Based on result and discussion of the research, average of work productivity of tea picker in PTP Nusantara VI Kayu Aro is $5.55 \mathrm{~kg} / \mathrm{h}$ and average income of tea picker female worker that gained by picking tea is Rp. 727,637.27/months by contribution of $58.31 \%$. Statistic analysis result by Rank Spearman correlation test has known that factors of responsibility family member, motivation, and perception to income has significant correlation to the productivity level of tea picker female worker in PTP Nusantara VI Kayu Aro. Factors of age, formal education, work experience and perception to company facilities have not a significant correlation to the productivity level.
\end{abstract}

Keyword : Productivity, Contribution, Female Worker of Tea Pickers

\section{PENDAHULUAN}

Industri perkebunan teh merupakan industri yang sangat rentan terhadap perubahan dinamis lingkungan. Produktivitas tenaga kerja yang tinggi merupakan salah satu variabel penting dalam keunggulan persaingan (Hadisuwito seperti dikutip oleh Masyhuri 1999). Dari seluruh tenaga yang dibutuhkan oleh perkebunan teh diperkirakan $75 \%$ dari jumlah tersebut adalah karyawan pemetik (Setiawati 1991). Menurut Dolimonthe seperti dikutip oleh Budiyanto (2003), permasalahan utama yang dihadapi oleh perkebunan teh dewasa ini adalah ketersediaan tenaga pemetik yang cenderung berfluktuasi dari tahun ke tahun. Hal ini antara lain disebabkan oleh persaingan yang semakin ketat dengan sektor lain yang membutuhkan tenaga kerja dalam jumlah 
banyak. Persaingan untuk mendapatkan tenaga kerja membawa dampak negatif bagi sebagian perkebunan teh. Beberapa memiliki jumlah pemetik per satuan luas sudah begitu kecil sehingga potensi pucuk di lapangan tidak tergali secara maksimal. Sementara itu, pada perkebunan teh yang lain jumlah pemetik per satuan luas panen sudah terlalu besar sehingga produktivitas menurun.

Pentingnya arti produktivitas dalam peningkatan kesejahteraan nasional telah disadari secara universal. Tidak ada jenis kegiatan manusia yang tidak mendapatkan keuntungan dari produktivitas yang ditingkatkan sebagai kekuatan untuk menghasilkan lebih banyak barang-barang atau jasa. Dengan meningkatkan produktivitas maka akan terjadi peningkatan langsung pada standar hidup yang berada di bawah kondisi distribusi yang sama dari perolehan produktivitas yang sesuai dengan masukan kerja.

Perkebunan teh Kayu Aro di Kabupaten Kerinci Propinsi Jambi merupakan perkebunan teh tertua di Indonesia, dibuka antara tahun 1925-1928 oleh Perusahaan Belanda, Namblodse Venotschaaf Handle Veriniging Amsterdam (NV HVA). Hingga kini, pabrik yang sudah berusia 74 tahun ini menghasilkan teh hitam Orthodox \pm 6 Juta kilogram per tahunnya. PT Nusantara VI Kayu Aro telah memberikan kesempatan kerja yang cukup besar di Indonesia. Untuk memenuhii kebutuhan akan tenaga kerja, pihak perkebunan memanfaatkan tenaga kerja yang berada di sekitar lokasi perkebunan terutama untuk tenaga kerja pemetik teh yang sebagian besar adalah tenaga kerja wanita (Anonimous 2006).

Untuk mencapai produksi yang tinggi ini tentunya peranan tenaga kerja dalam suatu perusahaan menjadi faktor yang mendukung dalam meningkatkan produktivitas. Berdasarkan uraian di atas maka dapat dirumuskan permasalahan yaitu (a) berapa besar tingkat produktivitas tenaga kerja wanita pemetik teh di PTP Nusantara VI Kayu Aro, (b) faktor-faktor apa saja yang berhubungan dengan produktivitas tenaga kerja wanita pemetik teh di PTP Nusantara VI Kayu Aro, (c) berapa besar tingkat penghasilan tenaga kerja wanita pemetik teh di PTP Nusantara VI Kayu Aro dan (d) berapa besarnya kontribusi penghasilan wanita pemetik teh terhadap penghasilan keluarga.

\section{METODOLOGI PENELITIAN}

Penelitian dilaksanakan di PTP Nusantara VI Kayu Aro Kabupaten Kerinci Propinsi Jambi, dari tanggal 15 Juli s.d 15 Agustus 2006. Penentuan lokasi dilakukan secara sengaja (purposive) dengan pertimbangan bahwa perusahaan ini merupakan perusahaan yang memperkerjakan 
tenaga kerja pemetik teh yang cukup banyak dan belum adanya penelitian yang mengenai produktivitas tenaga kerja pemetik teh pada perusahaan ini.

Responden dalam penelitian ini adalah Karyawan Harian Tetap ( KHT) pemetik teh di PTP. Nusantara VI Kayu Aro. Pengambilan sampel dilakukan dengan menggunakan metode acak sederhana (Simple Random Sampling) di mana tiap unit populasi mempunyai peluang yang sama untuk terpilih sebagai sampel (Nazir 1998). Sampel diambil 10\% dari populasi, menurut Hadi dikutip oleh Heryanto (1997).

Tabel 1. Jumlah Populasi Tenaga Kerja Wanita Pemetik Teh pada Daerah Penelitian

\begin{tabular}{cccc}
\hline No. & Afdeling & $\begin{array}{c}\text { Populasi } \\
\text { (Orang) }\end{array}$ & $\begin{array}{c}\text { Sampel } \\
\text { (10\% Populasi) }\end{array}$ \\
\hline 1. & $\mathrm{~A}$ & 122 & 12 \\
2. & $\mathrm{~B}$ & 95 & 10 \\
3. & $\mathrm{C}$ & 117 & 12 \\
4. & $\mathrm{D}$ & 137 & 14 \\
5. & $\mathrm{E}$ & 137 & 14 \\
6. & $\mathrm{~F}$ & 132 & 13 \\
7. & $\mathrm{G}$ & 139 & 14 \\
8. & $\mathrm{H}$ & 132 & 13 \\
\hline Jumlah & & 1011 & 102 \\
\hline
\end{tabular}

Sumber : PTP Nusantara VI Kayu Aro, 2006

Pengumpulan data dalam penelitian ini berasal dari dua sumber yaitu data primer dan data sekunder. Untuk mengetahui besarnya penghasilan karyawan pemetik teh, maka digunakan analisis deskriptif dengan menggunakan ukuran verbal dan tabel.

Untuk mengetahui produktivitas tenaga kerja wanita pemetik teh di PTP. Nusantara VI Kayu Aro digunakan rumus (Kusryanto, 1991) sebagai berikut :

$$
\text { produktivitas }=\frac{\text { Jumlah produksi }(\mathrm{Kg})}{\text { Jumlah satuan waktu } \operatorname{ker} \text { ja }(\mathrm{Jam})}
$$

Untuk mengetahui apakah ada hubungan antara variabel bebas $(X)$ dengan tingkat produktivitas tenaga kerja pemetik teh $(Y)$, maka data yang dikumpulkan dianalisa dengan uji korelasi Rank Spearman (rs) dan untuk menguji tingkat signifikasi maka digunakan uji t (Siegel, 1994) dengan rumus :

$$
t_{h i t}=r s \sqrt{\frac{N-2}{1-r s^{2}}}
$$


Dimana $t$ hitung dibedakan dengan $t$ tabel, dengan dua arah sisi dengan tingkat kepercayaan yang digunakan yaitu $95 \%(\alpha / 2=0,025)$.

Untuk mengetahui kontribusi Penghasilan tenaga kerja wanita pemetik teh terhadap Penghasilan keluarganya digunakan analisa deskripsi, dengan perhitungan :

Kontribusi pemetik teh $=\frac{\text { Penghasilan dari pemetikanteh }}{\text { Penghasilan keluarg } a} \times 100 \%$

Untuk pengkategorian variabel yang akan diteliti digunakan rentang nilai (interval) dengan rumus sebagai berikut :

$$
\text { Interval }=\frac{\text { Nilai Atas }- \text { Nilai Bawah }}{\text { Jumlah Kelas }}
$$

\section{HASIL DAN PEMBAHASAN}

\section{Produktivitas Kerja Pemetik Teh}

Pangestu seperti dikutip oleh Masyhuri (1999) mengartikan produktivitas tenaga kerja diartikan sebagai tingkat kemampuan tenaga kerja dalam menghasilkan produk. Menurut Hidayat seperti dikutip oleh Lediana (2005) produktivitas secara sederhana dan teknis diartikan sebagai rasio antara keluaran dan masukan yang tercapai, sehingga produktivitas dapat ditulis sebagai output per input.

Berdasarkan hasil pengukuran produktivitas pemetik teh di PTP Nusantara VI Kayu Aro diketahui tingkat produktivitas kerja pemetik teh adalah sebesar $566,537 \mathrm{~kg} / \mathrm{jam}$ dengan rata-rata $5,55 \mathrm{~kg} / \mathrm{jam}$. Untuk lebih jelas dapat dilihat pada Tabel 2 berikut :

Tabel 2. Produktivitas kerja pemetik teh

\begin{tabular}{lcccc}
\hline Produktivitas (kg/jam) & Jumlah & Persentase & Rata-rata & Kisaran \\
\hline Tinggi $(7,12-8,74)$ & 13 & 12,75 & & \\
Sedang $(5,49-7,11)$ & 36 & 35,30 & 5,55 & $3,85-8,74$ \\
Rendah $(3,85-5,48)$ & 53 & 51,96 & & \\
\hline
\end{tabular}

Sumber : Data Primer (hasil olahan.)

Dari rincian di atas dapat disimpulkan bahwa produktivitas kerja pemetik teh di PTP Nusantara VI Kayu Aro sebagian besar tergolong dalam kategori rendah dengan persentase melebihi 50 persen yaitu sebesar 51,96 persen. Hasil penelitian menunjukkan bahwa rendahnya 
produktivitas ini disebabkan sebagian pemetik teh ada yang belum memanfaatkan waktu kerja dengan baik.

\section{Faktor-Faktor yang Berhubungan dengan Produktivitas TenagaKerja Wanita Pemetik Teh}

Untuk membuktikan ada atau tidaknya hubungan antara variabel bebas dengan tingkat produktivitas tenaga kerja pemetik teh di PTP Nusantara VI Kayu Aro, maka digunakan uji korelasi Rank Spearman (rs). Hasil perhitungan koefisien korelasi Rank Spearman (rs) dapat dilihat pada Tabel 3 sebagai berikut.

Tabel 3. Hasil uji korelasi rank spearman dan nilai t hitung antara variabel bebas dengan tingkat produktivitas tenaga kerja pemetik teh di PTP. Nusantara VI Kayu Aro.

\begin{tabular}{lllll}
\hline No & \multicolumn{1}{c}{ Variabel Bebas } & \multicolumn{1}{c}{$\begin{array}{c}\text { Nilai } \\
\text { Korelasi }\end{array}$} & \multicolumn{1}{c}{ T hitung } & $\begin{array}{c}\text { Derajat } \\
\text { Hubungan }\end{array}$ \\
\hline 1 & Umur & $-0,04214$ & $-0,42177$ & Tidak nyata \\
2 & Pendidikan Formal & 0,00845 & 0,08450 & Tidak nyata \\
3 & Pengalaman Kerja & 0,11650 & 1,17299 & Tidak nyata \\
4 & Jumlah Tanggungan Keluarga & 0,35233 & 3,76471 & $\left(^{*}\right)$ \\
5 & Motivasi Kerja & 0,68593 & 9,42642 & $\left(^{*}\right)$ \\
6 & Persepsi Terhadap Upah & 0,86463 & 17,20968 & $\left(^{*}\right)$ \\
7 & Persepsi Terhadap Fasilitas & $-0,17183$ & $-1,74414$ & Tidak nyata \\
\hline
\end{tabular}

Sumber : Data Primer (hasil olahan).

Keterangan : $\left(^{*}\right)=$ Berhubungan nyata pada tingkat kepercayaan $95 \%(\alpha / 2=0,025)$ dengan nilai t tabel $+/-1,983494$

Dari Tabel 3 dapat disimpulkan bahwa faktor tanggungan keluarga, motivasi kerja dan persepsi tehadapan upah berhubungan nyata dengan produktivitas kerja pemetik teh, sedangkan faktor umur, pendidikan formal, pengalaman kerja dan persepsi terhadap fasilitas perusahaan tidak berhubungan nyata terhadap produktivitas tenaga kerja pemetik teh.

\section{Umur}

Hasil analisis diperoleh bahwa koefisien korelasi umur terhadap tingkat produktivitas tenaga kerja pemetik teh sebesar $-0,04214$ dan tidak nyata secara statistik, dimana t hitung $(-0,42177)>-t$ tabel $(-1,983494)$. Dengan demikian hipotesa alternatif $(\mathrm{Ha})$ ditolak sebaliknya hipotesa nihil $(\mathrm{Ho})$ diterima, hal ini berarti variasi umur pemetik teh wanita di PTPN VI Kayu Aro tidak menyebabkan variasi pada tingkat produktivitas, atau dengan kata lain faktor umur tidak berhubungan dengan tingkat produktivitas.

Pada penelitian ini, faktor umur tidak berhubungan dengan tingkat produktivitas tenaga kerja dikarenakan rata-rata wanita pemetik teh di PTP Nusantara VI Kayu Aro berada pada usia yang relatif produktif dengan rata-rata 43,30 tahun sehingga mereka masih dapat bekerja dengan baik meskipun usia mereka bertambah. 


\section{Pendidikan Formal}

Hasil analisis diperoleh bahwa koefisien korelasi pendidikan formal terhadap tingkat produktivitas tenaga kerja pemetik teh sebesar 0,00845 dan tidak nyata secara statistik dimana $t$ hitung $(0,08450)<t$ tabel $(1,983494)$. Dengan demikian hipotesa nihil $(\mathrm{Ho})$ diterima dan hipotesa alternatif $(\mathrm{Ha})$ ditolak, yang berarti pendidikan forma tidak berhubungan nyata dengan tingkat produktivitas.

Tidak terdapatnya hubungan nyata antara tingkat pendidikan formal ini dengan tingkat produktivitas disebabkan karena untuk pekerjaan sebagai pemetik teh tidak dibutuhkan suatu pendidikan formal tertentu, sebagian besar pemetik teh wanita di PTPN VI Kayu Aro memiliki pendidikan formal yang rendah. Hal ini dapat dilihat dari kenyataan di lapangan, di mana pemetik teh melakukan pemetikan hanya dipelajari dengan cara melihat dari rekan kerja yang lebih senior atau petunjuk dari mandor.

\section{Pengalaman Kerja}

Hasil yang diperoleh dari uji korelasi menunjukkan bahwa pengalaman kerja tidak berhubungan nyata dengan produktivitas pemetik teh wanita di PTPN VI Kayu Aro, di mana koefisien korelasinya sebesar 0,11650 dan tidak nyata secara statistik dimana t hitung $(1,17299)<$ t tabel (1,983494). Dengan demikian hipotesa nihil (Ho) diterima dan hipotesa alternatif $(\mathrm{Ha})$ ditolak, yang berarti pengalaman kerja tidak berhubungan nyata dengan tingkat produktivitas.

Dari wawancara yang dilakukan dengan responden, pekerjaan memetik teh adalah pekerjaan yang mudah untuk dilakukan dan tidak membutuhkan waktu yang banyak untuk mempelajari cara memetik teh sehingga masa kerja atau lamanya mereka bekerja memetik teh tidak menjadi penyebab produktivitas mereka dalam memetik teh.

\section{Jumlah Tanggungan Keluarga}

Uji korelasi pada variabel jumlah tanggungan keluarga menunjukkan bahwa jumlah tanggungan keluarga berhubungan nyata dengan tingkat produktivitas pemetik teh wanita di PTPN VI Kayu Aro dimana nilai korelasinya sebesar 0,35233 serta nyata secara statistik melalui hasil uji $\mathrm{t}$, dimana t hitung $(3,76471)>t$ tabel $(1,983494)$. Dengan demikian hipotesa alternatif (Ha) diterima atau hipotesa nihil $(\mathrm{Ho})$ ditolak, hal ini berarti jumlah tanggungan keluarga pemetik teh memiliki hubungan dengan produktivitas.

Dari hasil penelitian di lapangan, dapat diketahui bahwa dengan semakin banyaknya jumlah tanggungan keluarga maka produktivitas tenaga kerja pemetik teh akan semakin meningkat begitu juga sebaliknya produktivitas akan menurun dengan semakin sedikitnya jumlah 
tanggungan keluaarga. Dengan banyaknya tanggungan keluarga, maka pengeluaran semakin besar dan kebutuhan juga semakin tinggi sehinggga tenaga kerja pemetik teh wanita akan bekerja lebih giat lagi untuk memenuhi kebutuhan keluarganya dengan cara meningkatkan hasil petikannya.

\section{Motivasi}

Hasil penelitian menyatakan bahwa motivasi kerja berhubungan nyata dengan tingkat produktivitas tenaga kerja wanita pemetik teh di PTPN VI Kayu Aro. Hal ini terbukti dari nilai koefisien korelasi sebesar 0,68593 dengan nilai $t$ hitung $(9,42642)>t$ tabel $(1,983494)$. Selanjutnya hipotesa alternatif $(\mathrm{Ha})$ terbukti dan dapat diterima, sebaliknya hipotesa nihil $(\mathrm{Ho})$ ditolak.

Adanya korelasi positif ini dapat dinyatakan bahwa semakin tinggi motivasi kerja maka semakin tinggi pula tingkat produktivitas kerja pemetik teh wanita, atau sebaliknya semakin rendah motivasi kerja semakin renah pula produktivitas kerja pemetik teh.

\section{Persepsi Terhadap Upah}

Dari uji korelasi yang dilakukan memperlihatkan adanya hubungan yang nyata antara variabel persepsi terhadap upah dengan tingkat produktivitaas tenaga kerja wanita pemetik teh di PTPN VI Kayu Aro. Hal ini dapat dilihat dari nilai koefisien korelasi sebesar 0,86463 dengan nilai t hitung $(17,20968)>t$ tabel $(1,983494)$. Dengan demikian hipotesa alternatif $(\mathrm{Ha})$ terbukti dan dapat diterima, sebaliknya hipotesa nihil (Ho) ditolak.

Berdasarkan hasil penelitian menunjukkan adanya korelasi positf sehingga memberikan kesimpulan bahwa semakin baik persepsi terhadap upah yang diterima maka makin tinggi pula produktivitas kerja mereka, begitu pula sebaliknya semakin jelek persepsi terhadap upah maka semakin rendah pula tingkat produktivitasnya.

\section{Persepsi Terhadap Fasilitas Perusahaan}

Hasil analisis diperoleh bahwa koefisien korelasi persepsi terhadap fasilitas perusahaan terhadap tingkat produktivitas tenaga kerja pemetik teh sebesar $-0,17182$ dan tidak nyata secara statistik, dimana t hitung $(-1,74414)>-t$ tabel $(-1,983494)$. Dengan demikian hipotesa alternatif (Ha) ditolak sebaliknya hipotesa nihil ( $\mathrm{Ho}$ ) diterima, hal ini berarti persepsi terhadap fasilitas perusahaan tidak berhubungan dengan tingkat produktivitas pemetik teh wanita di PTPN VI Kayu Aro.

Tidak terjadinya hubungan yang nyata pada variabel persepsi terhadap fasilitas perusahaan dengan tingkat produktivitas kerja wanita pemetik teh berarti tenaga kerja pemetik teh 
yang memiliki persepsi yang tinggi terhadap fasilitas perusahaan ada yang memiliki produktivitas tinggi dan ada yang memiliki produktivitas rendah. Ini mencerminkan seperti apapun fasilitas yang disediakan oleh perusahaan, pemetik teh tetap bekerja sebgaimana basis yang telah ditetapkan. Mereka menganggap pemberian fasilitas dari perusahaan sudah cukup baik misalnya meliputi sarana dan prasarana dalam memetik teh seperti transportasi, caping, keranjang, rajut serta sarana umum seperti tempat tinggal, kesehatan, pendidikan, listrik, air bersih dan keamanan.

\section{Penghasilan Pemetik Teh dan Kontribusinya Terhadap Penghasilan Keluarga}

Penghasilan pemetik teh dari kegiatan memetik daun teh terdiri dari gaji bulanan, premi dan tunjangan sosial. Rincian tingkat penghasilan dapat dillihat pada Tabel 4 berikut.

Tabel 4. Penghasilan pemetik teh (Juli 2006)

\begin{tabular}{lcccc}
\hline \multicolumn{1}{c}{ Penghasilan (Rp/bulan) } & Jml & Persentase & Rata-rata & Kisaran \\
\hline Tinggi $(795.533,4-867.734)$ & 8 & 7,84 & & \\
Sedang $(723.332,8-795.533,3)$ & 37 & 36,27 & $727.637,27$ & $651.132-867.734$ \\
Rendah $(651.132-723.332,7)$ & 57 & 55,88 & & \\
\hline
\end{tabular}

Sumber : Data Primer (hasil olahan).

Berdasarkan Tabel 4 terlihat bahwa penghasilan pemetik teh yang diterima dari hasil kegiatan memetik daun teh di PTP Nusantara VI Kayu Aro rata-rata Rp 727.637,27/bulan dengan kisaran Rp 651.132/bulan sampai dengan Rp 867.734/bulan. Pemetik teh yang memiliki penghasilan tinggi sebanyak 7,84 persen, penghasilan rendah sebanyak 55,88 persen dan penghasilan sedang sebanyak 36,27 persen.

Penghasilan masing-masing pemetik teh berbeda, perbedaan ini terjadi karena setiap pemetik teh mempunyai produktivitas yang berbeda. Produktivitas dalam penelitian ini diduga berhubungan dengan faktor umur, pendidikan formal, pengalaman kerja, jumlah tanggungan keluarga, persepsi terhadap upah, persepsi terhadap fasilitas perusahaan dan motivasi kerja. Pada kenyataannya, setiap faktor tersebut memiliki perbedaaan antara pemetik yang satu dengan pemetik lainnya. Hal tersebut yang menyebabkan masing-masing pemetik teh memiliki kemampuan, ketelitian dan semangat yang berbeda sehingga menyebabkan penghasilan yang mereka peroleh dari perusahaan tidak sama.

Hasil penelitian menunjukkan bahwa perbedaan tingkat penghasilan tenaga kerja wanita pemetik teh di PTP Nusantara VI Kayu Aro disebabkan adanya perbedaan premi borong yang diterima oleh masing-masing pemetik teh. Semakin banyak Pucuk Teh Segar (PTS) yang melebihi 
basis borong semakin besar pula premi yang akan diterima oleh pemetik teh, sehingga menambah penghasilan yang mereka terima.

Berdasarkan hasil penelitian ternyata pekerjaan sebagai pemetik teh di PTPN VI Kayu Aro memberikan kontribusi yang cukup besar yaitu sebesar $58,31 \%$ terhadap penghasilan keluarga. Hal ini berarti perempuan pada umumnya memiliki peran ganda yang dijalaninya selain sebagai ibu rumah tangga dapat menyelesaikan pekerjaan rumah tangga juga berperan dalam membantu perekonomian keluarga melalui kegiatan memetik teh.

Tabel 5. Rata-rata Kontribusi Penghasilan dari Kegiatan Memetik Teh terhadap Penghasilan Keluarga per Bulan

\begin{tabular}{lrrrr}
\hline \multirow{2}{*}{ Keluarga } & \multicolumn{5}{c}{ Sumber Penghasilan } \\
\cline { 2 - 5 } & \multicolumn{1}{c}{ Memetik teh } & \multicolumn{1}{c}{ Suami } & \multicolumn{1}{c}{$\%$} \\
\hline Suami & 0,00 & 0,00 & $721.637,21$ & 39,06 \\
Istri & $727.637,27$ & 58,31 & 0,00 & 0,00 \\
Anak & 0,00 & 0,00 & 0,00 & 0,00 \\
Angg. Klg. lain & 0,00 & 0,00 & 0,00 & 0,00 \\
\hline Total & $727.637,27$ & 58,31 & $721.637,21$ & 39,06 \\
\hline
\end{tabular}

Sumber : Data primer (hasil olahan).

Tabel 6. Rata-rata Kontribusi Penghasilan Lain terhadap Penghasilan Keluarga per Bulan

\begin{tabular}{lrc}
\hline \multirow{2}{*}{ Sumber Penghasilan } & \multicolumn{2}{c}{ Sumber Penghasilan } \\
\cline { 2 - 3 } & Jumlah & $\%$ \\
\hline Anak & 0,00 & 0,00 \\
Angg. Klg. Lain & 0,00 & 0,00 \\
Sektor pertanian & $31.188,112$ & 2,64 \\
\hline Total & $31.188,112$ & 2,64 \\
\hline
\end{tabular}

Sumber : Data primer (hasil olahan)

Dari Tabel 5 menunjukkan bahwa penghasilan dari suami memberikan sumbangan sebesar 39,06 persen terhadap penghasilan keluarga, sementara dari sektor pertanian (Tabel 6) sebesar 2,64 persen terhadap penghasilan keluarga. Penghasilan dari sektor lain tenaga kerja wanita pemetik teh pada PTP Nusantara VI Kayu Aro merupakan penghasilan di luar kegiatan memetik teh meliputi penghasilan anak, penghasilan anggota keluarga lain dan penghasilan dari sektor pertanian. Penghasilan yang bersumber dari sektor pertanian adalah usaha-usaha pertanian milik keluarga tenaga kerja wanita pemetik teh yang dapat menambah penghasilan keluarga. Dari hasil penelitian, sumber penghasilan dari sektor pertanian yang pada umumnya dimiliki oleh keluarga tenaga kerja wanita pemetik teh di PTP Nusantara VI Kayu Aro adalah ternak, sawah, palawija, hortikultura, tanaman tahunan dan sebagai buruh pertanian. 


\section{KESIMPULAN DAN SARAN}

\section{Kesimpulan}

Penelitian ini menyimpulkan hal-hal sebagai berikut.

1. Produktivitas tenaga kerja pemetik teh di PTP Nusantara VI Kayu Aro memiliki rata-rata 5,55 $\mathrm{kg} / \mathrm{jam}$.

2. Faktor tanggungan keluarga, motivasi, dan persepsi terhadap upah mempunyai hubungan yang nyata positif terhadap tingkat produktivitas tenaga kerja wanita pemetik teh di PTP Nusantara VI kayu Aro, sementara faktor umur, pendidikan formal, pengalaman kerja dan persepsi terhadap fasilitas perusahaan tidak tidak berhubungan nyata.

3. Rata-rata penghasilan wanita pemetik teh di PTP Nusantara VI Kayu Aro dari hasil memetik teh sebesar Rp 727.637,27/ bulan.

4. Kontribusi penghasilan wanita pemetik teh di PTP Nusantara VI Kayu Aro terhadap penghasilan keluarga adalah sebesar $58,31 \%$.

\section{Saran}

Produk teh di PTP Nusantara VI Kayu Aro sangat dipengaruhi oleh banyaknya Pucuk Teh Segar (PTS) yang dipetik oleh para tenaga kerja pemetik teh wanita. Agar produktivitas meningkat, maka pihak perusahaan hendaknya memperhatikan tingkat kesejahteraan tenaga kerja pemetik mereka agar para tenaga kerja ini memiliki persepsi yang baik mengenai upah sehinggga meningkatkan motivasi untuk memenuhi standar dari perusahaan atau bahkan memberikan yang terbaik bagi perusahaan.

\section{DAFTAR PUSTAKA}

Anonimous. 2006. Selayang Pandang Kebun Kayu Aro. PTPN VI Kayu Aro. Tertanggal 1 Januari.

Budiyanto dkk. 2003. Analisis Kebutuhan Tenaga Pemetik Teh di PT. Sarana Mandiri Mukti. Kepahiang. Jurnal Penelitian UNIB. Bengkulu.

Kusryanto. 1991. Meningkatkan produktivitas Tenaga Kerja Karyawan. PT. Pustaka Binawan Peresindo. Jakarta.

Lediana. 2005. Faktor-Faktor yang Berhubungan dengan Produktivitas Tenaga Kerja Pemetik Teh di PT. Sarana Mandiri Mukti. Kepahyang. Skripsi FE. UNIB. Bengkulu. (tidak dipublikasikan)

Masyhuri. 1999. Produktivitas Tenaga Kerja Sektor Aneka Industri : Persfektif Sosial. http://pk.ut.ac.id/si/91masyhuri.htm.31k. (diambil tanggal 14 Februari 2006)

Nazir. 1998. Metode Penelitian. Ghalia Indonesia. Jakarta.

Setiawati, I. 1991. Teh, Kajian Sosial Ekonomi. Aditya Media. Jakarta.

Siegel.S. 1994. Statistik Nonparametrik. Gramedia. Jakarta. 